\title{
Intelligent control of induction motor without speed sensor
}

\author{
M. Elgohary, E. Gouda, S. S. Eskander \\ Department of Electrical Engineering, Faculty of Engineering, Mansoura University, Egypt
}

\begin{tabular}{l} 
Article Info \\
\hline Article history: \\
Received Mar 16, 2021 \\
Revised Apr 5, 2021 \\
Accepted Apr 13, 2021 \\
\hline
\end{tabular}

\section{Keywords:}

ANN speed estimator Indirect rotor field oriented control

Induction motor

Particle swarm optimization

PI controller

\begin{abstract}
This paper presents a proposed sensorless algorithm for induction motor (IM) speed control based on artificial neural networks (ANNs). The Indirect rotor field oriented (IRFO) technique is applied to control the motor. It is designed based on the proportional integral (PI) controller. The particle swarm optimization (PSO) algorithm is used as a good solution for the problems associated with the design of the proportional integral (PI) controller gains. The PSO is compared with the conventional methods. The proposed controller (PSO-PI) is then integrated with the artificial neural network (ANN) speed estimator. The MATLAB/Simulink is used for the simulation of the system. The obtained simulation results for the proposed technique are very close to the actual ones.
\end{abstract}

This is an open access article under the CC BY-SA license.

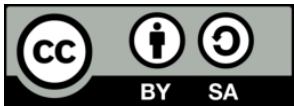

\section{Corresponding Author:}

Mohamed Elgohary

Department of Electrical Engineering

Mansoura University

35516 Mansoura, El Gomhouria street 25, Egypt

Email: mohamedyae1919@mans.edu.eg

\section{INTRODUCTION}

The induction motors (IMs) are considered the horsepower of industry. They have many advantages compared to other types. Therefore, they are used in large sections due to the simple construction design, ruggedness and low maintenance. Unfortunately, their speed controller design is considered a great challenge due to the nonlinearity of motor model [1].

Several techniques are used to control the IM. These techniques can be classified as scalar control or volts/hertz (V/f) [2] and vector control which can be classified into field oriented control (FOC) [3] and direct torque control (DTC) [4]. Most of the drives have employed vector control especially FOC techniques for the last three decades thanks to their advantage compared to V/f and DTC methods. the controller based on the V/f and DTC cannot realize the desired performance through transient operation since they consider the motor model in steady state [1], [5]. The classical DTC performance also degraded especially for low speed operating conditions because it has variable switching frequency high ripples in flux and torque [6].

The FOC techniques have a great attention, since it solves the problems of other controllers and make the speed control of IM as of separately excited DC-motors [5]. The IRFOC [7], [8] is the most widely used because of its insensitivity to the stator resistance change.

Classical proportional integral (PI) is a simple linear controller which can achieve IM control based on the FOC phenomena. Though, the PI controller has main drawbacks such as the mismatch between the model parameters and the actual model and un-modeled and nonlinear dynamics [8], these troubles make the tuning process of the controller is difficult and may cause instability in the system. There are many researches to overcome the problems of conventional selection of PI controller gains (Kp, Ki) which depend on using Artificial Intelligent (AI) techniques such as particle swarm optimization (PSO) and genetic 
algorithm (GA) [9]-[13]. Tista Banerjee, Sumana Chowdhuri, Gautam Sarkar, et al., [14] introduces a comparison between Zigler-Nichol method and the AI (GA and PSO). The comparison of their results shows the better of both AI techniques than Zigler-Nichol one but the PSO has better performance such as simplicity, minimizing the computational time and it has stable convergence characteristics compared to GA. In this paper the PSO is selected to make tuning of PI gains.

The approach of speed sensorless controls for IMs have been getting more interest in different industrial applications because they can make cost reduction and evade the problems associated with the mechanical speed sensors. Also, they remove the installing difficulty of the speed sensors in some applications [15], [16]. There are different techniques for estimating the IM speed and its rotor flux. These techniques can be classified as, (i) signal injection methods [16], the main drawbacks of these techniques are the causing of torque ripples, vibration and audible noise. Furthermore, motors having low saliency content do not give an appreciable response, (ii) open loop speed estimation techniques, there are two main techniques voltage or stator model and current or rotor model [17]. These approaches depend heavily on the motor parameters, (iii) model reference adaptive system (MRAS) [18], this method has the integration problem which may lead the system to instability, (iv) full order and reduced order closed loop observers. There are many approaches for these techniques, such as adaptive observer [19] which uses a complex gain in the feedback signal, sliding mode observer (SMO) [20], which has chattering carried out due to the high switching gain. Extended Kalman filter EKF has been proposed in [21] as a solution for better flux estimation. These approaches contain some inherent disadvantages such as highly computational processes [20], (v) artificial intelligent (AI) methods like artificial neural networks (ANNs) and fuzzy logic (FL) [22][24]. These techniques have a great attention in the last decades in many fields especially pattern recognition and control systems since they can deal with the complex or non-linear process without the needing for the relations between the input and output [25]. The FL was employed with MRAS in [21]. The ANN technique used with MRAS in [23]. The results were good but still depend on the motor parameters and lost the basic advantage of the AI techniques which make them more adequate to deal with the system with parameters independently.

This paper introduces a new technique for IRFOC of IM using ANN technique as a speed estimator. The proposed technique estimates the motor speed independently of the motor parameters and equations this make the proposed system more robust and unaffected to the motor parameter variations. The system efficient improved using PSO to calculate the controller gains directly from the system.

This paper is organized as follows. The mathematical model of IM is presented in Section 2. Section 3 presents the conventional- and the proposed PSO- PI controllers for speed control of IM based on IRFOC. In Section 4, the speed estimator based on the ANN technique is evaluated., the simulation results using MATLAB/Simulink are presented for different operating conditions to validate the efficiency of the proposed sensorless technique in in Section 5. Finally, some conclusions are presented in Section 6.

\section{INDUCTION MOTOR MODELING}

A three- phase, squirrel cage IM is considered in this paper. The d-q reference frame model of the IM can be represented as [18].

$$
\frac{d}{d t}\left[\begin{array}{l}
i_{d s} \\
i_{q s} \\
\lambda_{d r} \\
\lambda_{q r}
\end{array}\right]=\left[\begin{array}{cccc}
-a_{1} & \omega_{e} & a_{2} & P a_{3} \omega_{r} \\
-\omega_{e} & -a_{1} & -P a_{3} \omega_{r} & a_{2} \\
a_{5} & 0 & -a_{4} & \omega_{s l} \\
0 & a_{5} & -\omega_{s l} & -a_{4}
\end{array}\right]\left[\begin{array}{c}
i_{d s} \\
i_{q s} \\
\lambda_{d r} \\
\lambda_{q r}
\end{array}\right]+\left[\begin{array}{cc}
c & 0 \\
0 & c \\
0 & 0 \\
0 & 0
\end{array}\right]\left[\begin{array}{c}
V_{d s} \\
V_{q s}
\end{array}\right]
$$

where, $\quad a_{1}=\frac{1}{\sigma l_{s}}\left(R_{s}+R_{r} \frac{l_{m}^{2}}{l_{r}^{2}}\right), a_{2}=\frac{1}{\sigma l_{s}}\left(R_{r} \frac{l_{m}}{l_{r}^{2}}\right), a_{3}=\frac{1}{\sigma l_{s}} \frac{l_{m}}{l_{r}}, a_{4}=\frac{R_{r}}{l_{r}}, a_{5}=\frac{R_{r} l_{m}}{l_{r}}, c=\frac{1}{\sigma l_{s}}, \sigma=1-\frac{l_{m}^{2}}{l_{r} l_{s}}=$ leakage coefficient and $\omega_{s l}=\omega_{e}-P \omega_{r}=$ Slip frequency (speed).

$\mathrm{V}_{\mathrm{ds}}, \mathrm{V}_{\mathrm{qs}}$ : d-and q-axis stator voltages $(\mathrm{V}), \mathrm{I}_{\mathrm{ds}}, \mathrm{I}_{\mathrm{qs}}$ : d-and q-axis stator currents $(\mathrm{A}), \mathrm{R}_{\mathrm{s}}, \mathrm{R}_{\mathrm{r}}$ : Stator and rotor resistances $(\Omega), \mathrm{L}_{\mathrm{s}}, \mathrm{L}_{\mathrm{r}}, \mathrm{L}_{\mathrm{m}}$ : Stator self, rotor self and mutual inductances $(\mathrm{H})$, P: Number of poles pairs, $\lambda_{\mathrm{ds}}, \lambda_{\mathrm{qs}}$ : d-and q- axis stator fluxes $(\mathrm{Wb}), \lambda_{\mathrm{dr}}, \lambda_{\mathrm{qr}}: \mathrm{d}-$ and $\mathrm{q}-$ axis rotor fluxes $(\mathrm{Wb})$, $\omega_{\mathrm{e}} \omega_{\mathrm{r}}, \omega_{\mathrm{sl}}$ : Synchronous, rotor, slip speed $(\mathrm{rad} / \mathrm{s})$. The electromagnetic developed torque of the IM can be expressed as.

$$
T_{e}=\frac{3}{2} \frac{P l_{m}}{l_{r}}\left(\lambda_{d r} i_{q s}-\lambda_{q r} i_{d s}\right.
$$

The mechanical of IM.

Int J Pow Elec \& Dri Syst, Vol. 12, No. 2, June 2021 : $715-725$ 


$$
\dot{\omega}_{r}=\frac{1}{J}\left(T_{e}-B \omega_{r}-T_{l}\right)
$$

where, $\mathrm{T}_{1}$ : load torque (Nm), B: Coefficient of viscous friction (Nm.s/rad), J: Moment of inertia $\left(\mathrm{kg} \cdot \mathrm{m}^{2}\right)$.

\section{PI CONTROL DESIGN}

Since the PI controllers are widely used in IM drives and proved to be simple and effective. A PI controller is designed to control the IM speed as illustrated in Figure.1. Based on the IRFOC principle, the stator current component of the flux $\left(i_{d s}\right)$ is aligned with the direction of flux of the rotor $\left(\lambda_{r}\right)$ and the stator current of the torque $\left(i_{q s}\right)$ is aligned with the vertical direction to it as shown in Figure 2, for this situation:

$$
\lambda_{q r}=0, \dot{\lambda}_{q r}=0, \lambda_{d r}=\lambda_{r}=\text { rotor flux }
$$

then, the electromagnetic developed torque (2) cab be reduced to the next equation:

$$
T_{e}=\frac{3}{2} \frac{P l_{m}}{l_{r}}\left(\lambda_{d r} i_{q s}\right)=K_{t} \lambda_{d r} i_{q s}
$$

with $K_{t}=\frac{3}{2} \frac{P l_{m}}{l_{r}}$

Considering the field orientation condition, the dynamic model of the IM becomes.

$$
\frac{d}{d t}\left[\begin{array}{c}
i_{d s} \\
i_{q s} \\
\lambda_{d r}
\end{array}\right]=\left[\begin{array}{ccc}
-a_{1} & \omega_{e} & a_{2} \\
-\omega_{e} & -a_{1} & -P a_{3} \omega_{r} \\
a_{5} & 0 & -a_{4}
\end{array}\right]\left[\begin{array}{c}
i_{d s} \\
i_{q s} \\
\lambda_{d r}
\end{array}\right]+\left[\begin{array}{cc}
c & 0 \\
0 & c \\
0 & 0
\end{array}\right]\left[\begin{array}{c}
V_{d s} \\
V_{q s}
\end{array}\right]
$$

From (4) to (6), the relations can be obtained:

$$
\begin{aligned}
& i_{q r}=-\frac{L_{m}}{L_{r}} i_{q s} \\
& \lambda_{d r}=\frac{L_{m}}{1+T_{r} p} i_{d s} \\
& \omega_{s l}=\frac{L_{m}}{T_{r} \lambda_{d r}} i_{q s}
\end{aligned}
$$

In the steady state, $\lambda_{d r}=L_{m} i_{d s}$ and $i_{d r}=0$. To ensure the field orientation concept, the controller consists of three PI loops to control three interactive variables independently $\left(\lambda_{r}, T_{e}, \omega_{r}\right)$. The following two methods are illustrated for tuning the PI gains.

\subsection{Conventional method}

The IM can be represented by a simple model as shown in Figure1 depending (3) [27]. The whole equation for the closed-loop system is.

$$
\frac{\omega_{r}}{\omega_{r}^{*}}=\frac{K_{\omega} K_{p} S+K_{\omega} K_{i}}{\tau_{\omega} S^{2}+\left(1+K_{\omega} K_{p}\right) S+K_{\omega} K_{i}}
$$

where, $K_{\omega}=\frac{P}{B}$ is the motor gain, $\tau_{\omega}=\frac{J}{B}$, is mechanical time constant.

Assume a first order system for the (10) which can be presented by (11).

$$
\frac{\omega_{r}}{\omega_{r}^{*}}=\frac{1}{\tau_{c} S+1}
$$

where, $\tau_{c}$ is the closed-loop time constant of the system.

Solving (10) and (11) lead to the following parameters for the PI controller.

$$
K_{p}=\frac{\tau_{\omega}}{K_{\omega} \tau_{c}}, K_{i}=\frac{1}{K_{\omega} \tau_{c}}
$$




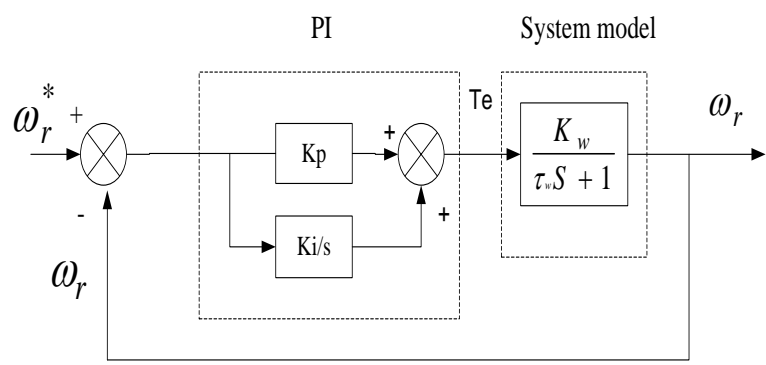

Figure 1. Closed loop PI controller

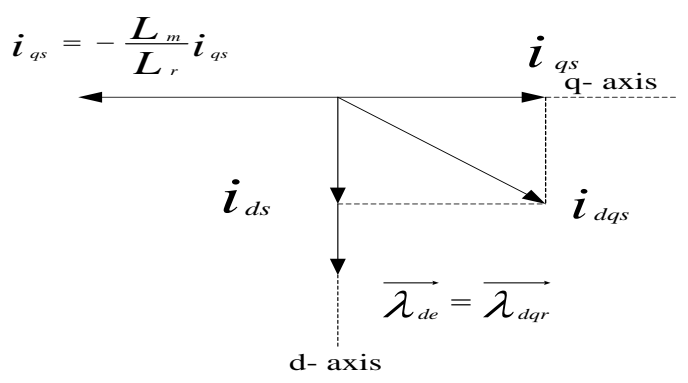

Figure 2. Phasor diagram of a field oriented IM

The (12) computes the PI controller parameters as a function of the mechanical time constant and the closed-loop time constant. This method has its disadvantages, it deals with the mechanical part of the system and doesn't take into account the effect of the inner control loops, so it needs to make an agree between outer and inner control loops, also it depends on try and error to get the best solution for different cases.

\subsection{Self-tuning PI controller}

Conventional control depends on using the mathematical model to control the system. When there are environmental disturbances or variations on the system parameters, these make the system performance is not fitting and diverges from the desired act. Furthermore, of the system mathematical model usual computations are difficult because the IM equations are complex and nonlinear dependent. This reduces the reliability of the system under control. To overcome these problems the tuning of the PI gains is done using PSO. The arrangement of the PSO algorithm with the PI controller is shown in Figure 3.

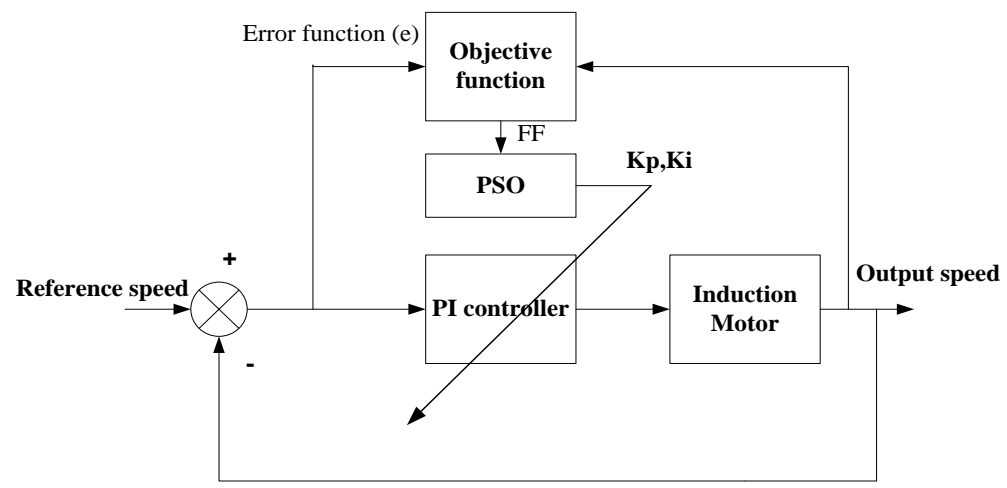

Figure 3. PSO algorithm with PI controller

The PSO algorithm is put directly in parallel with the simulated model, where it evaluates the PI gains according to a proposed fitness or objective function and its inherent structure. The design of PSO algorithm can be considered as a searching algorithm in which a group of particles $(i)$ are searching the target position in parallel and every iteration they update their position according to the global best results. The particle $i$ position can be improved by (13) [10]-[12].

$$
S_{i}^{k+1}=S_{i}^{k}+V_{i}^{K+1}
$$

where, $S_{i}^{k}$ is the previous position and $V_{i}^{K+1}$ is the new velocity which can be evaluated by (14) [12].

$$
V_{i}^{k+1}=C\left(w V_{i}^{k}+\left(c_{1} r_{1}\left(\text { pbest }_{i}-S_{i}^{k}\right)\right)+c_{2} r_{2}\left(\text { gbest }_{i}-S_{i}^{k}\right)\right)
$$

where, $V_{i}^{k}$ is particle $i$ previous velocity for iteration $\mathrm{k}, r_{l}$ and $r_{2}$ are random numbers, usually between $(0,1)$, pbest is the particle $i$ local best position, gbest is the particle $i$ global best position, $c_{l}$ is cognitive parameter 
and $c_{2}$ is social parameter and they must have a positive values, $w$ is weight function of the particle velocity. For fast convergence, it's recommended to use a varied value for the weight $\mathrm{w}$ starting from a high value and then decreased gradually to reach zero at the end of iteration process. Finally, $C$ is a constriction factor which used to get better choice of the parameters. The PSO has procedure, a) generate particles initial position, b) evaluate particles searching points using (13), c) modify particles searching points using (14), and d) repeat until reach the target or maximum iterations.

The proper choice of the fitness function is essential to get better performance. There are different essential standards which can be used as fitness function, more details in [6]-[8]. Integrated of time weight absolute error (ITAE) is one of the best standard formula which can be used as fitness function. Though, it is time dependent which mean it doesn't give the desired solution for small time operation. To overcome this problem, the absolute value of the overshoot in the tracked speed is considered with the ITAE function as.

$$
F F=I T A E+\mid \text { overshoot } \mid
$$

where,

$$
\operatorname{ITAE}=\int_{0}^{\infty} t|e(t)| d t
$$

\section{ANN SENSORLESS BASED TECHNIQUE}

The ANN can be described as a set of neurons that are connected in and organized in several layers [23] as shown in Figure 4. In this paper a Feedforward Neural Network (FFNN) is applied for speed estimation the IM motor. It's simple and fast compared to other types since it does not need a feedback signal. Then this estimator is used as a feedback signal to the controller instead of the actual one. The input signals of the ANN are changed consistent with the correlation weights. The error between chosen outputs and outputs of the ANN is minimized in the ANN learning process by updating the connection weights.

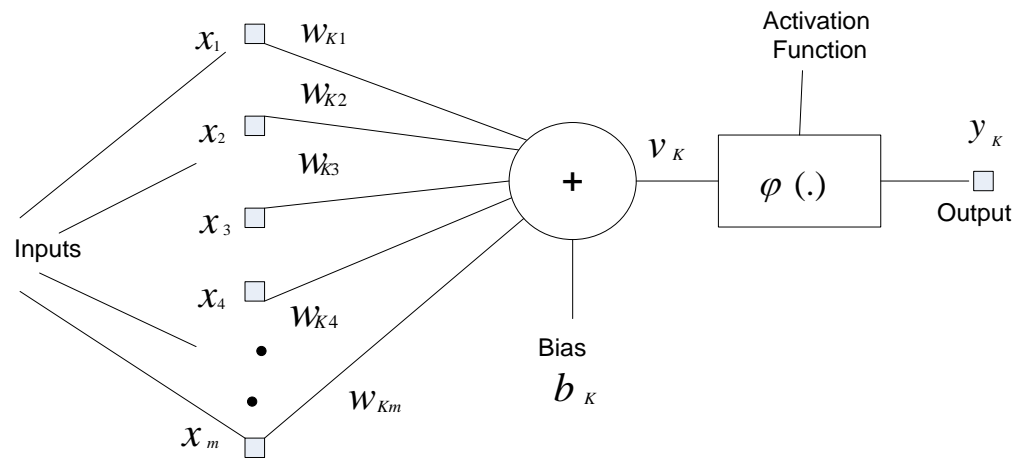

Figure 4. Typical model of ANN

The block diagram of the overall system of IM control with the proposed ANN speed estimator is shown in Figure 5. the ANN speed estimator consists of 3 layers (5- 10- 1). It has following structure, 5 inputs $\left(V_{\alpha s}, V_{\beta s}, I_{\alpha s}, I_{\beta s}, \omega_{r}\right)$ which are stationary voltages $\left(V_{\alpha s}, V_{\beta s}\right)$ and current components of the stator $\left(I_{\alpha s}\right.$, $\left.I_{\beta s}\right)$ as basic inputs and the reference speed $\left(\omega_{\mathrm{r}}\right)$ is added as input to the ANN to increase its fitness, one hidden layer with 10 nodes, finally one output layer with single node which gives the estimated motor speed.

The selected ANN was designed and trained using MATLAB/Simulink and combined with the PI controller where, the activation function used is a sigmoid unipolar function, and Levenberge -Marquardt algorithm is applied in data training. The whole iterations number is 1000 epoch. From the training results; the mean square error is 0.0485 for PI controller as shown in Figure 6. 


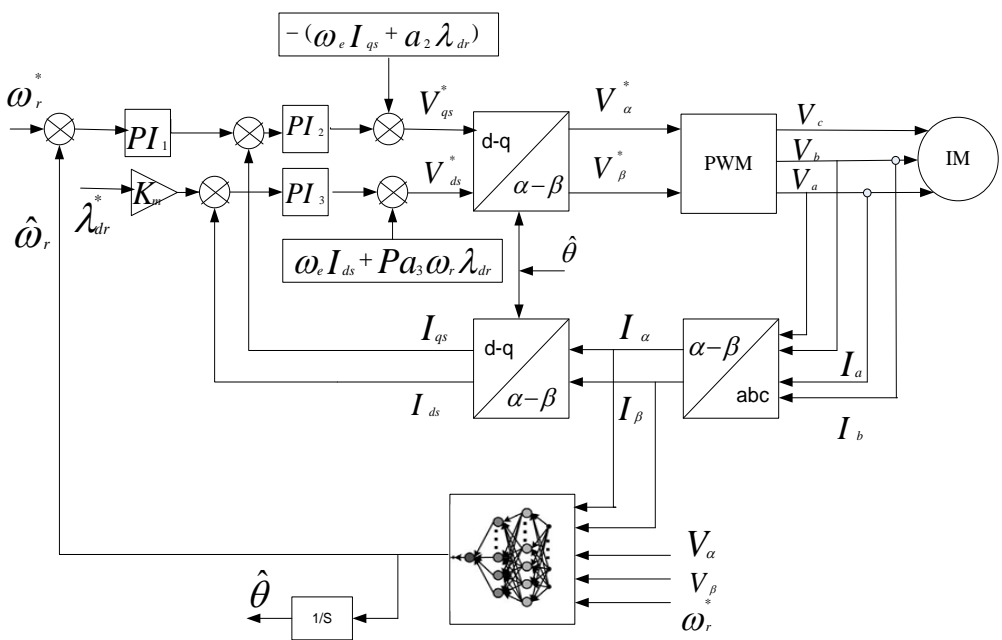

Figure 5. Sensorless IRFOC based on ANN estimator

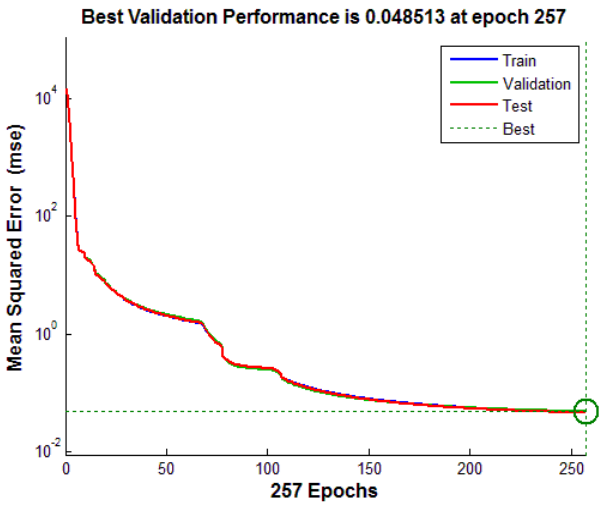

Figure 6. Mean-square error for the ANN under study

\section{SIMULATION RESULTS}

The control scheme of Figure 5 is applied using MATLAB/Simulink program. The IM nominal parameters which used for the simulation are given in Table 1.

\section{$P S O$-PI controller parameters}

The MATLAB program was used to perform the PSO algorithm, the parameters of the PSO algorithm are given in Table 2 .

the PI gains are optimized, and their values are presented as follows:

Speed loop PI controllers; Kp1=0.51, Ki1=1.38, Kp2=392.884, Ki2=103380

Flux loop PI controller; Kp3=392.884, Ki3=103380

The system is tested for various operating conditions for speed tracking. The results are taken first for both PI controllers with speed sensors as shown in Figure 7 to Figure 12 to compare between the conventional and PSO-PI controllers. Then the ANN speed estimator is integrated with the PSO-PI controller under high speed and low speed operation to validate the control system for a wide speed range.

For Figure 7 and Figure 8, The speed reference is firstly increased from $100 \mathrm{rad} / \mathrm{s}$ to $120 \mathrm{rad} / \mathrm{s}$ at $\mathrm{t}=1 \mathrm{~s}$ and from $120 \mathrm{rad} / \mathrm{s}$ to $150 \mathrm{rad} / \mathrm{s}$ at $\mathrm{t}=3 \mathrm{~s}$. The reference $\mathrm{d}$-axis rotor flux linkage is remained at $0.45 \mathrm{~Wb}$ without external loading. These figures show that the proposed PSO is more effective than the conventional one, where conventional PI controller has $20 \%$ maximum overshoot, Figure 7 , while PSO-PI controller, shown in Figure 8, has 2.9\% maximum overshoot. Also, from the figures it is shown that the PSO decreased the raising time. Figure 9 shows the ITAE for the two cases. It's seen that the value of ITAE is almost the same for two controllers along the first second although they have a different speed response, so the selection of fitness function of PSO depends only on the ITAE can't be effective in small time simulation. This was considered 
and the value of overshoot was added to the fitness function. The ITAE response for other case is shown in Figure 12, which also shows a good response than conventional-PI controller.

Table 1. IM nominal parameters

\begin{tabular}{cc}
\hline Motor Parameter & Value \\
\hline Output Power & $0.75 \mathrm{~kW}, 3$-ph \\
Speed & $1440 \mathrm{rpm}$ \\
Line voltage & $220 \mathrm{~V}, \mathrm{Y}$-connected \\
Current & $3 \mathrm{~A}$ \\
Frequency, f & $50 \mathrm{~Hz}$ \\
Number of pair poles, P & 2 \\
$\mathrm{R}_{\mathrm{s}}, \mathrm{R}_{\mathrm{r}}$ & $6.37,4.3 \Omega$ respectively \\
Ls, Lr, Lm & $0.26,0.26,0.24 \mathrm{H}$ \\
Moment of inertia, J & $0.0088 \mathrm{Kg} . \mathrm{m}^{2}$ \\
B & $0.003 \mathrm{Nm} . \mathrm{s} / \mathrm{rad}$ \\
\hline
\end{tabular}

Table 2. PSO Parameters

\begin{tabular}{cl}
\hline PSO Parameter & Value \\
\hline Number of iterations & 150 \\
Number of particles & 20 \\
$w$ & 1.1 \\
$c 1, c 2$ & 2 \\
$C$ & 0.8 \\
\hline
\end{tabular}

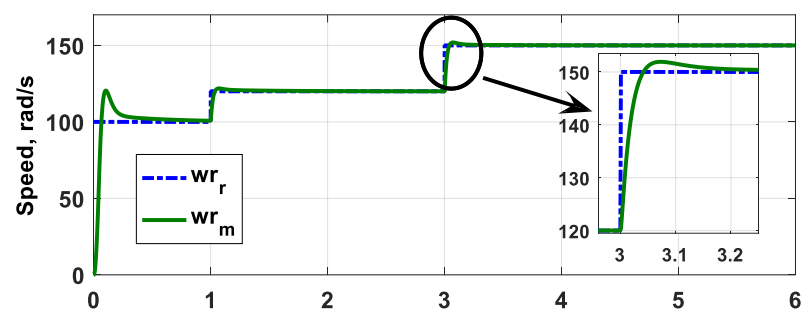

(a)

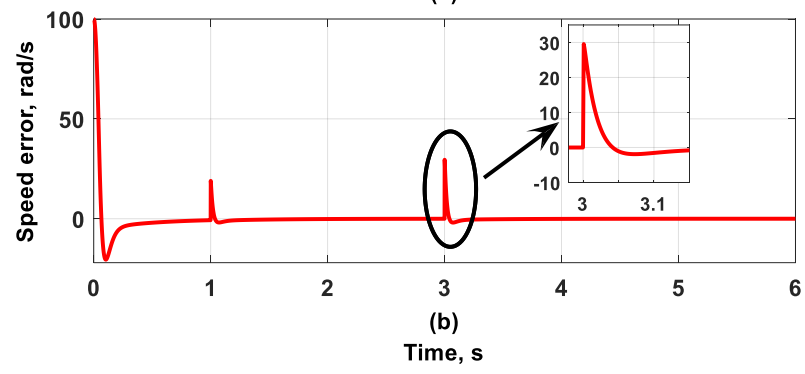

Figure 7. Reference speed step change with conventional PI controller, (a) Speed, (b) Speed error

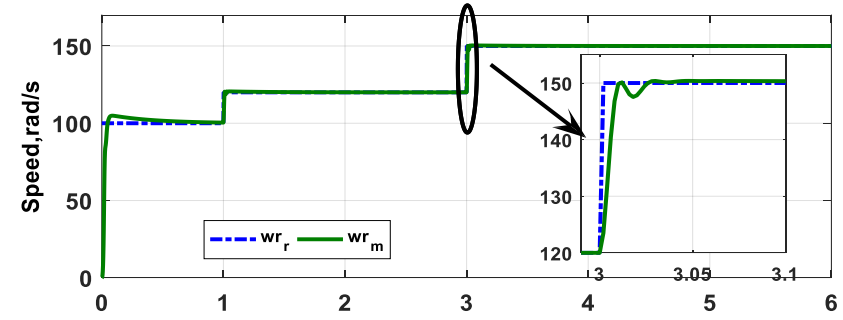

(a)

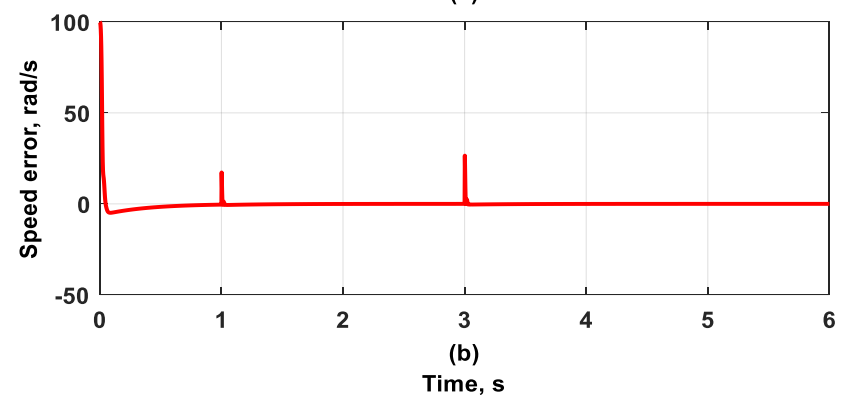

Figure 8. Reference speed step change with PSO-PI controller, (a) Speed, (b) Speed error 


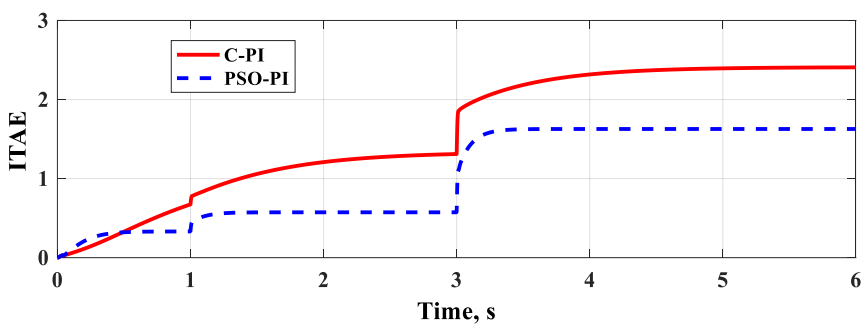

Figure 9. ITAE response for conventional and PSO-PI controller under step reference speed

For the second case the motor loading: the reference speed is changed in a trapezoidal way for studying the control system tracking performance for both directions also an external load with $5 \mathrm{Nm}$ (nominal value) is applied between intervals $1.4 \mathrm{~s}$ to $2.3 \mathrm{~s}$ and between $3.9 \mathrm{~s}$ to $4.8 \mathrm{~s}$ to study the robustness of the system under sudden applied loads. The results are better for PSO and the system is return to steady state quickly compared to the conventional PI controller.

Now the PSO-PI controller is tested for speed estimation with high speed command Figure 13 and low speed command which results is presented in Figure 14. By analyzing the last figures it's obvious that the suggested estimator has a valid response with different speed references. Figure 13 shows the increase of the speed reference starting from zero to $100 \mathrm{rad} / \mathrm{s}$ gradually then step change to $15 \mathrm{rad} / \mathrm{s}$ and finally reduced to $75 \mathrm{rad} / \mathrm{s}$ in all cases the system response is high and has a very small error between the actual speed and estimated one as shown in Figure 13 (c). the final case is the operating the system at low speed, Figure 14 in this case the reference speed is taken as a trapezoidal starting the motor operation at $0.6 \mathrm{~s}$ with maximum speed value of $15 \mathrm{rad} / \mathrm{s}$. The figure shows that the system is still capable of working and track the reference speed at acceptable behavior.
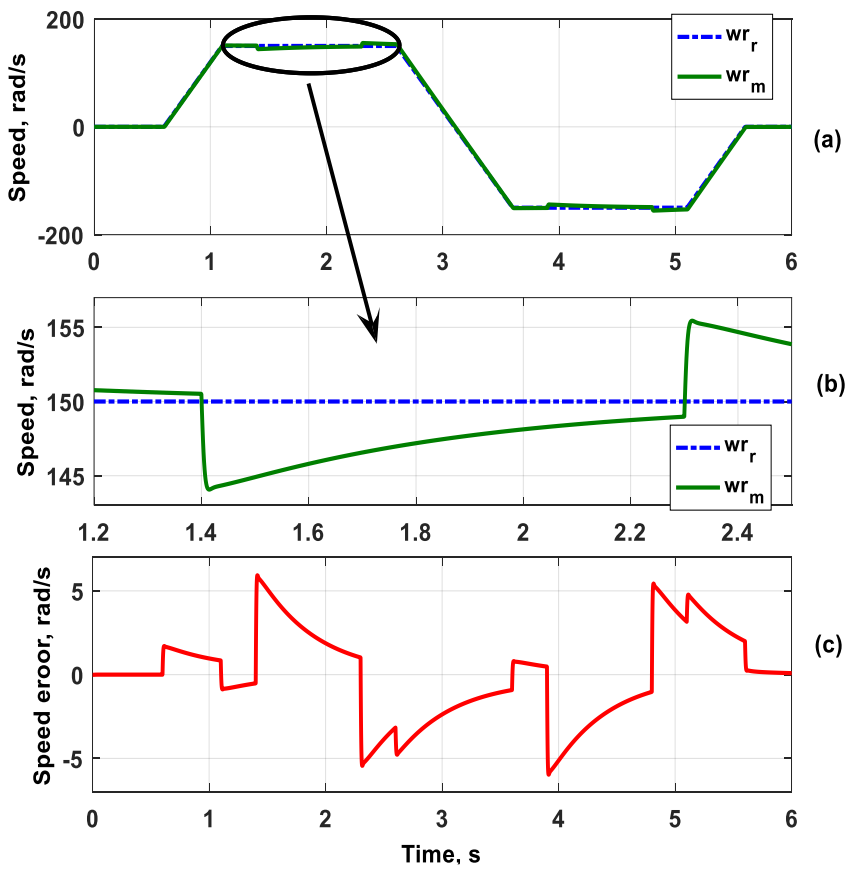

Figure 10. loading condition with conventional PI controller, (a) Speed response, (b) Focus on speed, (c) Speed error 


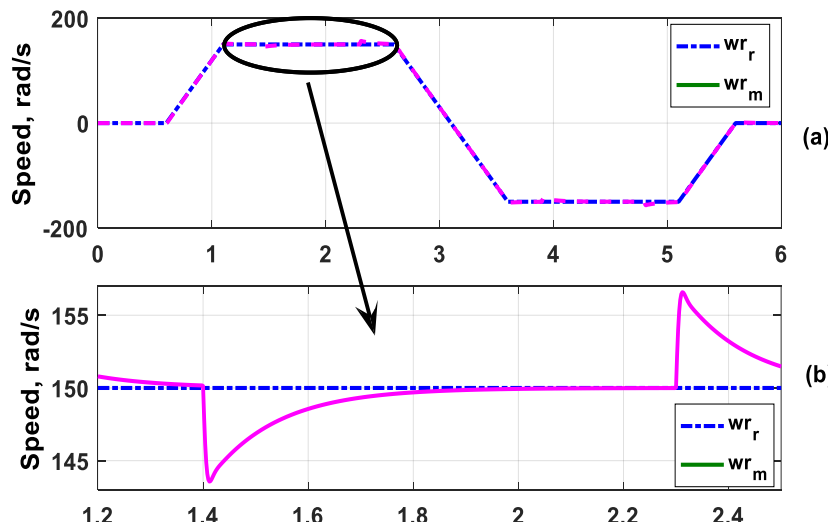

(a)

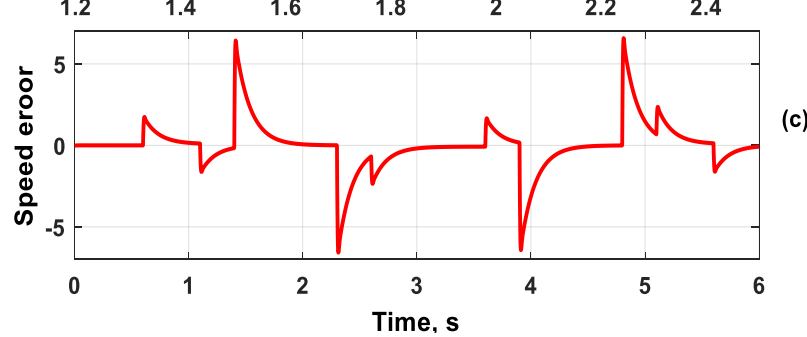

Figure11. loading condition with PSO-PI controller, (a) Speed response, (b) Focus on speed, (c) Speed error

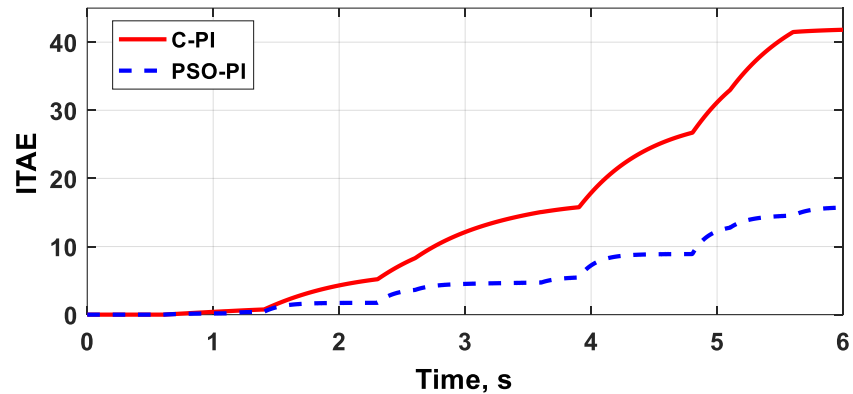

Figure12. ITAE response for conventional and PSO-PI controller under trapezoidal reference speed
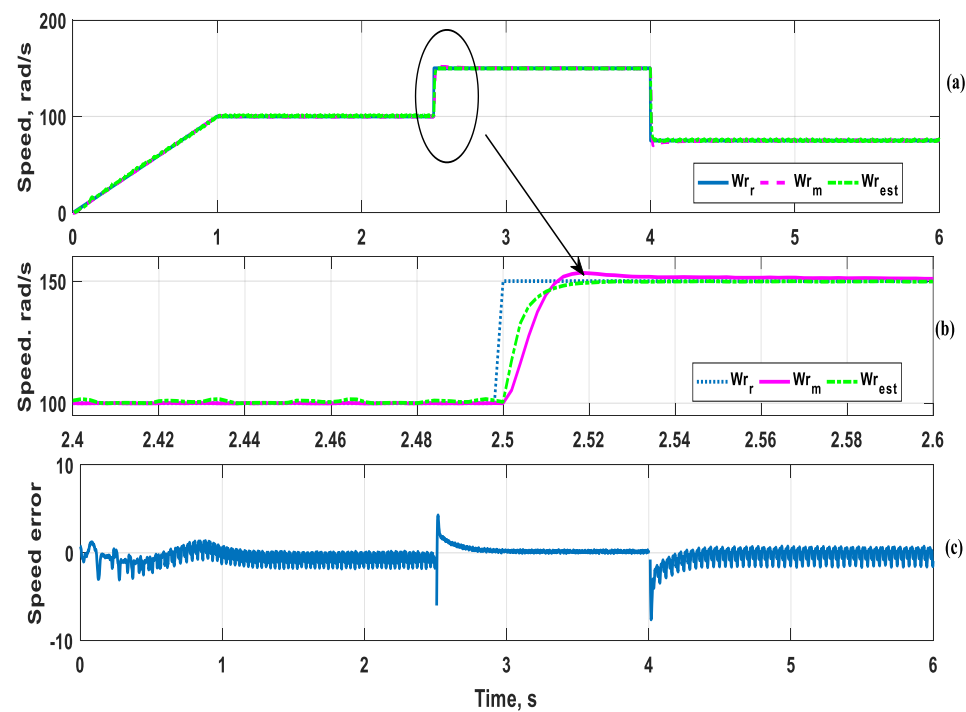

Figure 13. Step reference speed with PSO-PI controller; (a) Results for all simulated time, (b) Focus on the results,(c) Speed error 

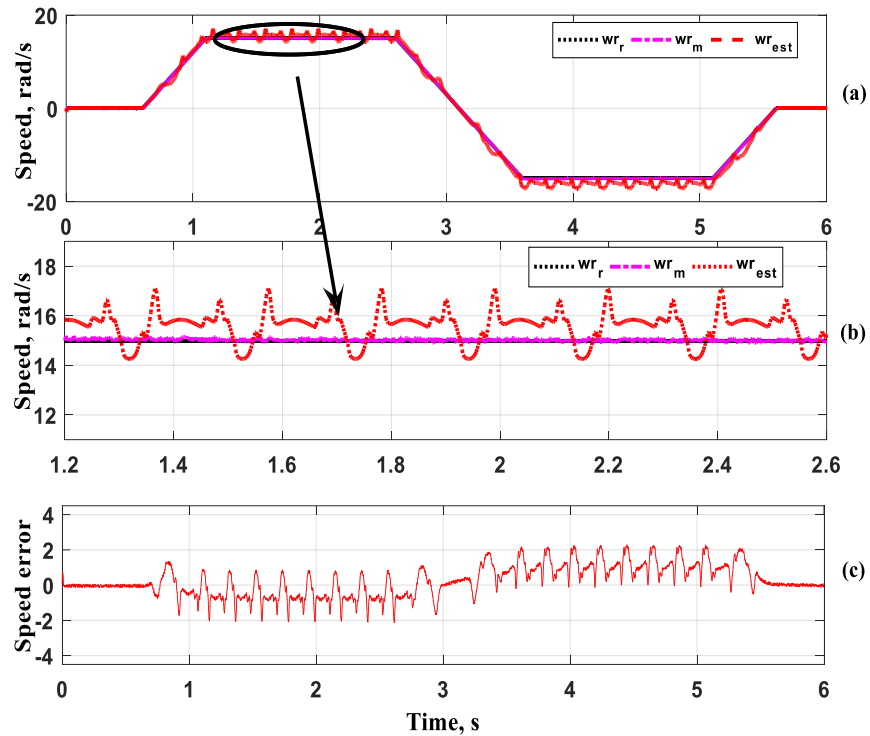

Figure14. Low speed condition with PI controller, (a) Results for all simulated time, (b) Focus on the results, (c) Speed error

\section{CONCLUSION}

This paper presented a proposed technique for IM speed control without speed sensor based IRFOC technique using FFNN as a speed estimator. The control technique was designed using PI controllers. The PI gains were tuned based on two different methods, the conventional and proposed method based on the PSO algorithm. The results were taken to compare the two methods. These results show that the proposed tuning method has good response comparing to the conventional method especially for step response where the overshot was decreased to about $3 \%$ instead of $20 \%$ for the other one with decreasing the raising time and setting time. After that the speed estimator was designed based on the FFNN. The results were taken for various operating situations which show the efficiency for the sensorless technique especially at high speeds where the error was around $2 \%$ and has an acceptable value at low speed operations. The future work for this paper includes verifying of the proposed system using experimental validation and enhancing the speed estimation under very low speed operation.

\section{REFERENCES}

[1] M.A. Hannan, Jamal A. Ali, Azah Mohamed, and Aini Hussain, "Optimization techniques to enhance the performance of induction motor drives: a review," Renewable and Sustainable Energy Reviews, vol. 81, no. Part 2, pp. 1611-1626, 2018, DOI: 10.1016/j.rser.2017.05.240

[2] Siti Nursyuhada Mahsahirun, Nik Rumzi Nik Idris, Zulkifli Md. Yusof, and Tole Sutikno, "Fundamental elements of constant volt/hertz induction motor drives based on dSPACE DS1104 controller," International Journal of Power Electronics and Drive System (IJPEDS), vol. 11, no. 4, pp. 1670-1685, 2020, DOI: 10.11591/ijpeds.v11.i4.pp1670-1685

[3] Chaymae Laoufi, Zouhair Sadoune, Ahmed Abbou, and Mohammed Akherraz, "New model of electric traction drive based sliding mode controller in field-oriented control of induction motor fed by multilevel inverter," International Journal of Power Electronics and Drive System (IJPEDS), vol. 11, no. 1, pp. 242-250, 2020, DOI: 10.11591/ijpeds.v11.i1.pp242-250

[4] S. Allirani, N. Subha Lakshmi, and H. Vidhya, "Performance analysis on direct torque controlled induction motor drive with varying hysteresis controller bandwidth," International Journal of Power Electronics and Drive System (IJPEDS), vol. 11, no. 3, September 2020, pp. 1165-1174, 2020, DOI: 10.11591/ijpeds.v11.i3.pp11651174

[5] Venu Gopal B T, "Comparison between direct and indirect field oriented control of induction motor," International Journal of Engineering Trends and Technology, vol. 43, no. 6, pp. 364-369, January 2017, DOI: 10.14445/22315381/IJETT-V43P260

[6] Ibrahim Mohd Alsofyani, Yeongsu Bak, and Kyo-Beum Lee, "Fast torque control and minimized sector-flux droop for constant frequency torque controller based DTC of induction machines," in IEEE Transactions on Power Electronics, 2019, vol. 34, no. 12, pp. 12141-12153, DOI: 10.1109/TPEL.2019.2908631 
[7] V. M. Goswami and K. Vakharia, "High performance induction machine drive using rotor field oriented control," 2019 International Conference on Intelligent Sustainable Systems (ICISS), Palladam, Tamilnadu, India, 2019, pp. 559-564, DOI: 10.1109/ISS1.2019.8907959

[8] Y. Zidani, A. Boulmane and D. Belkhayat, "Improvement of the indirect field oriented control for IM drives using fuzzy controllers," 2019 6th International Conference on Electrical and Electronics Engineering (ICEEE), Istanbul, Turkey, 2019, pp. 45-49, DOI: 10.1109/ICEEE2019.2019.00016

[9] Ghoulemallah Boukhalfa, Sebti Belkacem, Abdesselem Chikhi and Said Benaggoune, "Genetic algorithm and particle swarm optimization tuned fuzzy PID controller on direct torque control of dual star induction motor," $J$. Cent. South Univ., vol. 26, no. 7, pp. 1886-1896, DOI: 10.1007/s11771-019-4142-3

[10] Z. Qi, Q. Shi and H. Zhang, "Tuning of digital PID controllers using particle swarm optimization algorithm for a CAN-based DC motor subject to stochastic delays," in IEEE Transactions on Industrial Electronics, vol. 67, no. 7, pp. 5637-5646, July 2020, DOI: 10.1109/TIE.2019.2934030

[11] R. Marouane and Z. Malika, "Particle swarm optimization for tuning PI controller in FOC chain of induction motors," 2018 4th International Conference on Optimization and Applications (ICOA), Mohammedia, Morocco, 2018, pp. 1-5, DOI: 10.1109/ICOA.2018.8370512.

[12] G. Shashibhushan and S. Sonoli, "Multi-objective solution with PSO algorithm for minimization of torque ripple and speed settling time by using solar-fed 11,9 and 3-level multi-level inverter with vector control of induction motor," International Journal of Power Electronics and Drive System (IJPEDS), vol. 11, no. 2, pp. 827-832, June 2020, DOI: 10.11591/ijpeds.v11.i2.pp827-832

[13] A. Ghasempour and M. B. Menhaj, "A new genetic based algorithm for channel assignment problem," Computational Intelligence, Theory and Applications, Ed. B. Reusch, Berlin: Springer, 2006, pp. 85-92, DOI: 10.1007/3-540-34783-6_10

[14] Tista Banerjee, Sumana Chowdhuri, Gautam Sarkar, and Jitendranath Bera, "Performance comparison between GA and PSO for optimization of PI and PID controller of direct FOC induction motor drive," International Journal of Scientific and Research Publications, vol. 2, no. 7, pp. 1-8, July 2012.

[15] Abdelkarim Ammar, Aissa Kheldoun, Brahim Metidji, TarekAmeid, and YounesAzzoug, "Feedback linearization based sensorless direct torque control using stator flux MRAS-sliding mode observer for induction motor drive," ISA Transactions, vol. 98, pp. 382-392, March 2020, DOI: 10.1016/j.isatra.2019.08.061

[16] Alejandro G. Yepes, Jesús Doval-Gandoy, Fernando Baneira and Hamid A. Toliyat, "Speed estimation based on rotor slot harmonics in multiphase induction machines under open-phase fault," IEEE Transactions on Power Electronics, vol. 33, no. 9, pp. 7980-7993, Sept. 2018, DOI: 10.1109/TPEL.2017.2773649

[17] Hussien MG, Xu W, Liu Y and Allam SM, "Rotor speed observer with extended current estimator for sensorless control of induction motor drive systems," Energies, vol. 12, no. 19, 2019, DOI: 10.3390/en12193613

[18] C.U. Reddy, K. K. Prabhakar, A. K. Sing, and P. Kumar, "Speed estimation technique using modified stator current error-based MRAS for direct torque controlled induction motor drives," IEEE Journal of Emerging and Selected Topics in Power Electrronics, vol. 8, no. 2, June 2020, DOI: 10.1109/JESTPE.2019.2901523

[19] B. Chen, Y. Wenxi, F. Chen, and L. Zhengyu, "parameter sensitivity in sensorless induction motor drives with the adaptive full-order observer," IEEE Transactions on Industrial Electronics, vol. 62, no. 7, 2015, DOI: 10.1109/TIE.2014.2388197

[20] Bo Wang, Zhixin Huo, Yong Yu, Cheng Luo, Wei Sun and Dianguo Xu, "Stability and dynamic performance improvement of speed adaptive full-order observer for sensorless induction motor ultralow speed operation," in IEEE Transactions on Power Electronics, vol. 35, no. 11, pp. 12522-12532, Nov. 2020, DOI: 10.1109/TPEL.2020.2987599

[21] Uma Syamkumar and B. Jayanand, "Real-time implementation of sensorless indirect field-oriented control of three-phase induction motor using a Kalman smoothing-based observer," International Transactions on Electrical Energy Systems, vol. 30, no. 2, 2020, DOI: 10.1002/2050-7038.12242

[22] B. Yassine, Z. Fatiha and L. Chrifi-Alaoui, "IS-MRAS with on-line adaptation parameters based on type-2 fuzzy logic for sensorless control of IM," Iranian Journal of Electrical and Electronic Engineering, vol. 16, no. 1, pp. 85-95.

[23] Archana Tiwari, Bhavnesh Kumar and Yogesh K. Chauhan, "ANN based RF-MRAS speed estimation of induction motor drive at low speed," 2017 International conference of Electronics, Communication and Aerospace Technology (ICECA), DOI: 10.1109/ICECA.2017.8212789

[24] Hamdi Echeikh, Ramzi Trabelsi, Hichem Kesraoui, Atif Iqbal, and Mohamed Faouzi Mimouni, "DTC-ANN-2level hybrid by neuronal hysteresis with mechanical sensorless induction motor drive using KUBOTA observer," International Journal of Power Electronics and Drive System (IJPEDS), vol. 11, no. 1, March 2020, pp. 34-44, DOI: 10.11591/ijpeds.v11.i1.pp64-74

[25] [H. Chaoui and P. Sicard, "adaptive fuzzy logic control of permanent magnet synchronous machines with nonlinear friction," IEEE Transactions on Industrial Electronics, vol. 59, no. 2, pp. 1123-1133, Feb. 2012, DOI: 10.1109/TIE.2011.2148678.

[26] M. O. Ajangnay, "Optimal PID controller parameters for vector control of induction motors," International Symposium on Power Electronics, Electrical Drives, Automation and Motion, IEEE, 2010, pp. 959-565, DOI: 10.1109/SPEEDAM.2010.5545043 